\title{
ARTICLE \\ Determination of Business Strategies Using SWOT Analysis; Planning and Managing the Organizational Resources to Enhance Growth and Profitability
}

\author{
Hamed Taherdoost $^{1^{*}} \quad$ Mitra Madanchian $^{2}$ \\ 1.Research Club (R\&D Department), Hamta Group; OBS Tech Limited, Vancouver, Canada \\ 2.Fairleigh Dickinson University (FDU); Hamta Group | Hamta Business Corporation, Vancouver, Canada
}

\begin{tabular}{l} 
ARTICLE INFO \\
\hline Article history \\
Received: 29 December 2020 \\
Accepted: 31 January 2021 \\
Published Online: 31 March 2021 \\
\hline Keywords: \\
SWOT \\
SWOT analysis \\
Business \\
Strategic planning \\
Business success \\
Growth and profitability
\end{tabular}

\section{Introduction}

Every organization needs business strategies to accomplish its goals in a specific timeline. Business strategies are known as high-level organizational plans that lead businesses towards their specific objectives ${ }^{[1]}$. Organizations search relevant data in their internal and external environment and by showcasing them through a SWOT analysis, provide different business scenarios that they may employ for the future of their business ${ }^{[5]}$.

SWOT analysis is a simple but at the same time effective technique that has been used in the planning and

\section{ABSTRACT}

A SWOT analysis is the method to evaluate the internal weaknesses and strengths of an organization as well as evaluating the threats and opportunities of its external environment. This is considered as an effective framework to plan and manage the organizational resources to achieve certain goals in a specific period of time. The purpose of implementing SWOT analysis in an organization is to formulate the strategy of a business based on existing internal and external factors. There may be several disadvantages associated with running a SWOT analysis; however, its efficiency in determining the future strategy of a business is more indeed. Although the origin of SWOT analysis is uncertain, there is a long historical background about its uses to facilitate the decision-making process in every complex environment. The final result of a SWOT analysis can be presented in a matrix which is a combination of the four factors and determines strengths and weaknesses that a company involves, with opportunities and threats that it may face. This article provides a study of SWOT analysis basics and provides several practical insights of steps to provide a SWOT matrix.

management process of various businesses for the last 60 years and is connected to the weaknesses, strengths, threats and opportunities. SWOT analysis is helpful for decision-makers to provide effective strategies, policies, and improvements by examining the conditions of their internal and external environment and specific capabilities of that company. These internal and external factors may help or harm the business. Therefore, SWOT analysis is based on strategic planning to gain new perspectives and ideas by evaluating internal and external elements along with the current and future potentials of the business ${ }^{[9]}$. Consequently, the actual work starts after the SWOT chart

*Corresponding Author:

Hamed Taherdoost,

Research Club (R\&D Department), Hamta Group; OBS Tech Limited, Vancouver, Canada;

Email: hamed.taherdoost@gmail.com 
is drawn.

To make a SWOT matrix, all aspects of the organization (various dimensions), as well as the opinions and views of all stakeholders, should be reviewed and unified to help understand the main trend or pattern of the company and ultimately achieve business goals. Accordingly, an identical version of SWOT cannot be used for all companies and every company needs a unique SWOT based on its situation, environment, and other relevant factors.

\section{Definition of the SWOT Analysis}

The SWOT framework involves a list of factors that affect the business objective and performance internally and externally. Opportunities and threats are posed by the external environment whereas strengths and weaknesses are related to internal issues.

Businesses use SWOT analysis as a strategic planning tool to ensure that their objectives are clearly defined for their future venture and project. Besides, this helps them to make sure that all factors that are relevant to their task, whether they are positive or negative, are identified clearly and also well-addressed. The SWOT analysis process involves considering four important areas including opportunities, threats, weaknesses and strengths. In the process of identifying important factors and classifying them, the focus is not solely limited to internal factors, but it is also about realizing external elements that may influence the success or failure of the organization ${ }^{[7]}$.

External opportunities and internal strengths help an organization to achieve its objectives. These are known as positive factors for organizations in the path of meeting their targets. On the other hand, external threats and internal weaknesses are known as factors that negatively affect the organization to achieve its objectives and are considered unfavorable for organizations. Therefore, determining any successful strategy for the future of businesses is a result of analyzing a selection of internal weaknesses and strengths in relation to the external opportunities and threats that are posed by the surrounding environment. In other words, a manager that plans the strategy for an organization should consider the analysis of internalities and externalities and plan a strategy that helps the organization to get the most out of its weaknesses and strengths in the light of external threats and opportunities ${ }^{[11]}$.

To identify the external and internal factors that every organization faces, a comprehensive analysis should be conducted. On one hand, these factors may be potential incentives for an organization. On the other hand, they could be factors that limit the organization to achieve its goals and intentions ${ }^{[10]}$. The result of the SWOT analysis can be presented in a matrix that is a combination of four areas reflecting internal and external factors. This will determine the final strategy that can guide an organization through its long-term progress ${ }^{[6]}$.

Items listed in a SWOT chart in every section of strength, weakness, opportunity, and threat influence each other (also have an impact on other aspects of the business) and make a matrix that results in a more complex SWOT but is an efficient way to solve the problems originated from the chart analysis. According to Figure 1, TRIZ model of a SWOT, internal organizational strengths provide opportunities and can also counteract weaknesses. Besides, weaknesses create threats and can also counteract opportunities. In addition, opportunities can be counteracted by threats ${ }^{[8]}$. It is important to note that it is not necessary to make a long list of items for each factor. It is important to have a fishbone model to see the reason why these items are considered as threats, opportunities, weaknesses and strengths ${ }^{[8]}$.

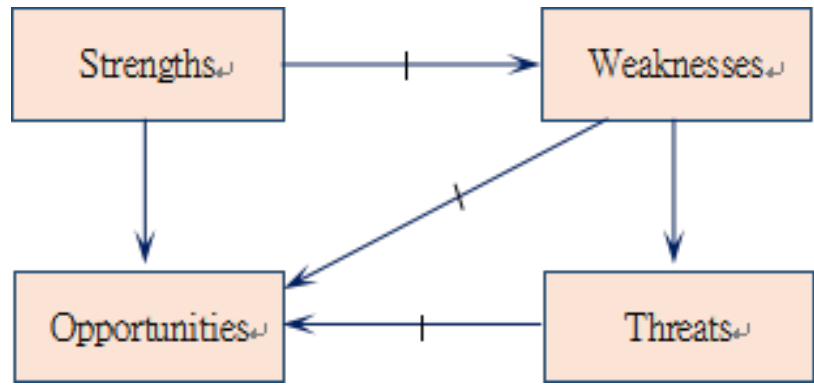

Figure 1. A TRIZ model of a SWOT chart [8]

\section{Main Purpose of Employing the SWOT Analysis}

The main purpose to use SWOT analysis is to approach new opportunities by empowering strengths and also to reduce or stop the progress of threats by recognizing and eliminating weaknesses in an integrated framework.

The integral purpose that SWOT follows to achieve is identifying the strategies that provide a business model for the firm that best fits its operations by employing organizational resources and specifications in alignment with environmental factors. SWOT is all about conducting a study to realize environmental factors that may affect the firm and finally use it as a tool to predict the future trends. This will facilitate the decision-making processes in organizations that have always been accompanied with difficulties $^{[7]}$.

Another common use of SWOT is in cases where an alternative appears all of a sudden and should be analyzed with regard to the decision-making process. SWOT analysis is generally known as a method to formulate the organizational strategy ${ }^{[10]}$. 
The purpose that managers and decision-makers follow by employing SWOT is to acquire a comprehensive understanding about all potential internal and external factors that may impact the success or failure of their projects. Any ignorance to identify a key weakness, strength, threat or opportunity may lead a business to make poor decisions ${ }^{[7]}$.

\section{Steps to Run a SWOT Analysis}

The following steps are considered as the main steps to run a SWOT analysis in different business:

(1)Find the objectives of carrying out a SWOT analysis.

(2)Investigate situations of the business, industry and market.

(3)Identify strengths of your business and list them.

(4)Realize weaknesses of your business as well as your industry and categorize them.

(5)Identify potential opportunities and perspectives of your industry and classify them

(6)List and organize potential threats for your business.

(7)Find priorities from the SWOT elements and analyze them.

(8)Develop a strategy that best addresses the issues and challenges of your internal and external environment ${ }^{[5]}$.

\section{Advantages and Disadvantages of the SWOT Analysis}

Collins-Kreiner and Wall state that SWOT analysis is a simple and at the same time useful method to organize information, specifically for preliminary research. They emphasize that it is also considered as a foundation for theoretical work ${ }^{[2]}$. One of the advantages of SWOT analysis that is also considered as a disadvantage at the same time is that it is known as the method of evaluation. The evaluation of the work is more applied than its theoretical ones.

SWOT is recognized as a useful method to understand the environment that an organization operates, and as a result, it would be beneficial in strategic planning that determines the future growth and development of a business [6]

Organizational policies and business strategies may change as a result of the dynamic digital era. Organizational or business structures may lead to complex issues and limitations. In these cases, there is a possibility for the SWOT analysis to fail. SWOT may be unsuccessful to help managers in their decision-making process by providing a great amount of information and data, and it may neither provide solutions for a business nor prioritize the challenges and issues ${ }^{[5]}$.

A number of advantages and disadvantages of the SWOT analysis are listed below:

\subsection{PROS}

1)Understanding the external factors as well as internal capabilities can be provided by referring to factual data;

2)There would be a chance for businesses for evaluating external opportunities and threats;

3)There would be a factual evaluation of organization's weaknesses and strengths in comparison to its competitors;

4) It provides a new understanding of the position of the organization in the competitive market;

\subsection{CONS}

1) It may be time consuming;

2)Past data may be used for analysis and accessibility to present data may be limited;

3)There may be different opinions as a result of differently analyzing the SWOT matrix;

4)Results are often a list of information with incomplete, superficial, or inaccurate items;

5 ) It is not possible to quantify the effect of strategic factors on alternatives ${ }^{[3,6]}$.

\section{Conclusions}

A SWOT analysis determines the strengths and weaknesses that a company involves, with opportunities and threats it may face. In the SWOT matrix, strengths are evaluated to identify the company's competitive advantages, weaknesses are assessed to identify the lack of vital firm capabilities, opportunities to identify new growth and development paths, and threats to change the company's external and environmental parts. The alignment of the factors listed in the SWOT matrix and the impact of each one on the other is important to be taken into account.

Some scientists, however, believe that in the SWOT matrix environmental factors are oversimplified in some cases and the results may even be far from reality. Nevertheless, many experts still consider SWOT, with all its flaws, an efficient method for strategic planning. SWOT analysis not only is a guide for business planning but also is a helping tool with personal decisions.

\section{References}

[1] Arnott, D. (2008) Success Factors for Data Warehouse and Business Intelligence Systems, AIS Electronic Library, ACIS 2008 Proceedings, Christchurch, New Zealand. 
[2] Collins-Kreiner, N.; Wall, G. 2007. Evaluating tourism potential: A SWOT analysis of the Western Negev, Israel. Tourism 55, 51-63.

[3] Foong, L M. 2007. Understanding of SWOT Analysis [online]. Available online from https:// article. tqmcasestudies.com/free-tqm-ebook/swot-analysis. pdf.

[4] Helms, Marilyn M.; Nixon, Judy. 2010. Exploring SWOT Analysis- where are we now? A review of academic research from the last decade. Journal of Strategy and Management, Vol. 3 No. 3, pp. 215-251.

[5] Namugenyi, Christine; Nimmagadda, Shastri L; Reiners, Torsten. 2019. Design of a SWOT Analysis Model and its Evaluation in Diverse Digital Business Ecosystem Contexts, Procedia Computer Science, Volume 159. Pages 1145-1154.

[6] Oreski, Dijana. 2012. Strategy development by using SWOT - AHP, TEM Journal - Volume 1 / Number 4 / 283-291.

[7] Osita, Ifediora; Onyebuchi R., Idoko; Justina, Nze- kwe. 2014. Organization's stability and productivity: the role of SWOT analysis an acronym for strength, weakness, opportunities and threat. International Journal of Innovative and Applied Research. Volume 2. 23-32.

[8] Smith, Howard. 2006. Process Innovation: P-TRIZ 6 beyond SWOT and Toward Change.

[9] Taherdoost, H., et al. 2014, Perceived Barriers and Benefits of Web Based Services, International Conference on Computational Science and Computational Intelligence, 10-13 March, Las Vegas, USA, Page: 34-38.

[10] Yuksel, I.; Dagdeviren, M. 2007. Using the analytic network process (ANP) in a SWOT analysis - A case study for a textile firm, Information Sciences 177: 3364-3382.

[11] Gürel, Emet; Tat, Merba. 2017. SWOT ANALYSIS: A THEORETICAL REVIEW. Journal of International Social Research. 10. 994-1006. 10.17719/ jisr.2017.1832. 